\title{
A System Model and An Innovation Approach toward Sustainable Housing Renovation
}

\author{
Ju Liu ${ }^{1, *}$, Bo Bengtsson ${ }^{2}$, Helena Bohman ${ }^{1}$ and Karin Staffansson Pauli ${ }^{1}$ \\ 1 Department of Urban Studies, Malmö University, Malmö SE-205 06, Sweden; helena.bohman@mau.se (H.B.); \\ karin.pauli@mau.se (K.S.P.) \\ 2 Department of Urban Studies, Malmö University and Institute for Housing and Urban Research, \\ Uppsala University, Uppsala SE-751 05, Sweden; bo.bengtsson@ibf.uu.se \\ * Correspondence: ju.liu@mau.se; Tel.: +46(0)734-416-738
}

Received: 4 December 2019; Accepted: 30 January 2020; Published: 5 February 2020

check for updates

\begin{abstract}
Housing renovation is a common concern to owners, tenants and to society at large. In addition to the high economic costs, the implementation of housing renovation usually have a long-term impact on the society and the built environment. This is a theoretical paper that develops a system model for understanding sustainable housing renovation as a system phenomenon which has multiple sustainability goals, complicated dynamic processes, diverse actors, and a sophisticated institutional environment. It identifies the key challenges of a sustainable housing renovation system, namely the conflicting sustainability goals and the conflicting stakeholder interests. To address these two challenges, the paper suggests an innovation approach in which the process of innovation (linear versus organic) and the typology of innovation (product versus process and business versus social) toward sustainable housing renovation are discussed.
\end{abstract}

Keywords: sustainability; housing renovation; conflicting sustainability goals; conflicting stakeholder interests; system; innovation

\section{Introduction}

In recent years, housing renovation has been increasingly accepted as an urgent issue for the economic, environmental and social sustainability of the society. In many European countries, houses built between 1970 and 1990 account for about one quarter of the total building stock and they are now facing major renovation needs [1]. In Sweden, around one million homes were built between 1965 and 1974, and they have now reached an age at which renovation is necessary [2]. The renovation of rental housing meets with some specific challenges because the housing company needs to deal with a number of different individual tenants in negotiation, persuasion and decision making. In this paper, the main focus is on rental housing renovation, but part of our argument also has some relevance to non-rental housing renovation.

Crucial to all forms of housing renovation is how to address the two challenges of the conflicting sustainability goals and conflicting stakeholder interests. In some circumstances, the sustainability goals, as framed as the triple-bottom-line (TBL) with economic, environmental and social aspects for sustainable development [3], are compatible in housing renovation. For example, reducing the waste of the construction material can reduce environmental impact and economic cost at the same time. However, in other situations, these goals are conflicting. For example, the installation of electrochromic smart window glass will let in beams of sunlight in winter and block some of the sun radiation in summer, thus saving energy without sacrificing indoor comfort. Unfortunately, such renovation will almost certainly increase the rent and consequently, exclude the economically disadvantaged population, such as single-parent families and pensioners. Hence, in this case, environmental sustainability is in 
conflict with social sustainability. The possible conflicts between economic, environmental and social goals may fundamentally undermine the potential of sustainable urban development. Furthermore, in addition to the potential conflicts between the three aspects of sustainability goals, the complex relation between the different stakeholders' interests makes housing renovation even more challenging. A renovation project involves a wide range of stakeholders, such as the owner/landlord, the tenants, the communities, the contractors, the government regulatory bodies, and so forth. These are all interest groups with different preferences and priorities. The widely discussed landlord-tenant dilemma [4] is a good example of such conflicts between stakeholder interests. For instance, if the tenant bears the cost of heating and electricity, the landlord has not much incentive to invest in energy efficiency while the tenants want to lower the electricity bill. When the payer is not the direct beneficiary, a dilemma of split incentives occurs. In such cases, the economic benefit of the real estate company is in conflict with the economic benefit of the tenants.

The conflicts among sustainability goals and the conflicts among stakeholder interests are not completely avoidable. What we can do is reducing the conflicts and expanding the shared and compatible parts in order to create a healthier balance between conflicting goals and interests. However, the conventional method of renovation cannot offer a solution. We need innovation to achieve sustainable housing renovation. In this paper, we suggest a system perspective and innovation approach as one way forward. Previous research on renovations has mainly been concerned with environmental sustainability, and energy efficiency in particular. A notable exception is Lind et al. [5], who focused on rent-setting and renovation. The present paper, in contrast, takes a holistic approach to the sustainability concept.

To analyse and understand the complexity of the housing renovation process we adopt a system perspective. A system perspective takes things as interrelated and interdependent parts-a system, in which the change of one part affects other parts as well as the whole system. The outcome of a system does not depend on a single actor's effort and performance but on the interaction of all the involved actors' actions and outputs. The actors do not act in a vacuum but in a systematic environment where rules and norms apply. Housing renovation is not only a set of technical activities conducted by a real estate company and their sub-contractors. It is a set of complicated social interactions among a wide range of heterogeneous stakeholders with enormous resources involved and complex rules and norms applied. The risk of overlooking certain goals in housing renovation is obvious, particularly the long-term ones and/or the ones that are held by economically and socially disadvantaged groups. The challenges of conflicting sustainability goals and conflicting stakeholder interests are system challenges rather than challenges only about technology or challenges only to a single organisation. Therefore, we argue that there is a need for a system framework that can be used to understand, evaluate, and guide housing renovation processes toward sustainability.

In order to tackle the problems of conflicting sustainability goals and conflicting stakeholder interests in housing renovation, we need new ways of thinking and new ways of managing. In other words, we need innovation. Innovation is the creation of new knowledge and the actualisation of new ideas to improve internal processes and structures and facilitate new business or organisational outcomes [6]. Innovation can be performed in relation to products, processes, services, operations and people [7]. Addressing one of these two conflicts is not an easy task, say nothing to the situation when the two types of conflicts intertwist. Addressing the double challenges of conflicting sustainability goals and conflicting stakeholder interests requires new processes of doing things, not only the engineering process of renovation per se but also the companies' management processes and the government's administrative process. It requires new technologies and materials, not only for construction but also for connecting and engaging people. It requires a new organisational design for coordination not only within the real estate company but also within the whole system that is involved. It requires new legislation not only for environment protection but also for social integration.

Nevertheless, in the area of sustainability research, there is generally a lack of guidance by models and frameworks [8]. Identifying models or frameworks for specific sustainability challenges is highly 
encouraged in the sustainability research community. The conventional project management tools, focusing on time, quality, and cost, do not offer effective measures to address the system challenge of conflicting sustainable goals and conflicting stakeholder interests. In the paper, we apply instead a broad system perspective on these complex relations and introduce a theoretical framework of housing renovation with innovation as a way to approach it.

This paper is theoretical, and its contribution is twofold. First, the paper develops a system model for understanding sustainable housing renovation. It adopts a system perspective combining the project processes, the sustainability goals, the stakeholders and the institutional environment to create a holistic picture of housing renovation as a system phenomenon rather than a set of engineering activities. Second, it introduces an innovation approach to housing renovation for better addressing the challenges of conflicting sustainability goals and conflicting stakeholder interests. The real estate industry is currently going through considerable structural change as a result of fast urbanisation, urgent social challenges, rapid technological change and increasing knowledge intensity of production. In this transitional phase, we see the prerequisites as particularly favourable for our paper to contribute to new knowledge and better understanding for innovation and sustainability in the real estate industry.

The paper consists of six sections. The following Section 2 first defines sustainable housing renovation based on the discussion about the existing concepts and models of sustainability and then discusses the concept of housing renovation. Section 3 defines and elaborates the system of sustainable housing renovation. Section 4 identifies the key challenges in the sustainable housing renovation system. Section 5 first introduces innovation as an approach to tackle the key challenges and then further discusses two important issues of the innovation approach: the process of innovation and the typology of innovation in housing renovation. Finally, Section 6 concludes the paper.

\section{Defining Sustainable Housing Renovation}

Housing renovations can be seen as a spectrum of different types of measures ranging from the relatively simple replacement of surface materials to fundamentally changing both interior and exterior aspects of a house. There are also a number of different concepts used synonymously or in similar meanings, such as refurbishment, restoration and retrofitting. We will use the term renovation for describing relatively extensive changes of a building mainly used for housing. Housing can, compared to other types of buildings, be considered more complex since it affects people at a very personal level. Major renovations may result in tenants having to move out of the buildings for longer periods of time, which can be challenging especially in areas where there is a housing shortage. Technologically, buildings used for housing also need to suit quite demanding needs since people tend to spend large and important part of their lives in their homes. Renovation processes are a complicated complex. Compared with the broad and necessary recognition of the economic and technical values of renovation, there is a risk of underestimating the architectural, cultural, and social values in housing renovation. In consequence, renovation should be considered a service-minded process rather than a merely technical one as is often the case in new construction [9]. In sum, renovation is a complex series of processes with considerable economic, environment and social impacts.

\subsection{Understanding Sustainability as A Multi-Dimensional Construct}

Sustainability is a multi-dimensional construct. First, it is a multi-scale concept that can be applied on the organisational level, the industrial level and the societal level. Second, it is a multi-scope concept containing economic, environment and social aspects. Sustainability, as defined by both scholars (e.g., Hart and Milsten [10]) and international organisations (e.g., UN [11]), refers to the expectations of improving the development performance of the present generation without compromising the ability of future generations to meet their needs. The definition thus highlights the long-term aspects of present performance, economic as well as non-economic.

Due to its simplicity and universality, this definition has been widely used. Nevertheless, the definition does not offer any framework to monitoring the activities, generating new solutions, 
and evaluating the performance of a company. It provides theoretical principles rather than practical guidelines. For understanding, e.g., how a real estate company can contribute to a sustainable urban development, the definition needs to be specified and operationalised into a theoretical framework to identify the content of activities, the criteria of evaluation and the direction in which to take action.

\subsection{Using the TBL Model as An Evaluation Framework and Practical Guideline for Sustainability}

The TBL model (economic line, environmental line, social line) or 3Ps (profit, planet, people) model [3] is a sustainability-related framework for evaluating a company's performance [12] as well as a practice guideline for sustainability [13]. It goes beyond the conventional corporate evaluation criteria, such as profit and revenue-long-term to be economically sustainable—by including measures concerning environmental and social impacts [14]. Such impacts lie both inside and outside the organisational boundary and they fundamentally affect the wider settings of the society in which the company operates and will operate. The TBL model has been widely and increasingly used as an accounting framework and practical guideline not only for companies but also for NGOs and government agencies. The triple pillars are considered as three independent but interrelated goals of sustainability.

The economic aspect of the TBL model is related to the activities that are conducted, e.g., by a firm, in order to add economic value to the surrounding system [15] in which the organisation operates and grows. The economic sustainability of a firm is a precondition for the firm's support to the future generations by means of generating employment, training human resources, etc. A firm's economic goals of sustainability may well be about profitability, growth rate, economic efficiency, etc., but in order to contribute to economic sustainability, the outcome must not compromise the ability of future generations to meet their needs. To a real estate company and any other economic organisation, the economic aspect of sustainability is the precondition of the other two aspects of sustainability.

The environmental aspect of the TBL model is related to the practices of a firm (or other actors) to reduce environmental impact and to create environmental benefit. The environmental sustainability of a firm is to ensure a liveable environment for future generations. A firm's environmental goals of sustainability may concern energy consumption, water efficiency, toxic waste prevention, etc. In terms of sustainable renovation, many previous studies focus on the environmental aspects such as reducing energy use $[4,16,17]$.

The social aspect of the TBL model is related to the practices that are beneficial and fair to the workers in the company and to people in the community [15]. The social sustainability of a firm, within the company as well as in the wider society, is an important part of the efforts of the whole society to promote social well-being, such as equality, justice, social capital, health, safety, quality of life, within the company as well as in the wider society. Lind et al. [5] discussed social sustainability in renovation and see social sustainability either as housing affordability or as the ambition to create mixed communities with 'a low level of segregation between different income and ethnic groups'. In reality, a firm's social goals of sustainability can go beyond fair access to resources or community integration; they can also include culture heritage protection, personal security, democracy, health, and so forth.

Notably, the TBL model has received criticism as well as further development. The criticism questions its enforceability and accountability [18], its measurability [19], its lack of integration [20], and its lack of a time dimension [21],. Based on the TBL model, in the past two decades, scholars have developed different bottom line models. For example, the quadruple bottom line (QBL), which extends the TBL by adding a fourth dimension, such as governance [22], or culture [23],. Another example is the integrated bottom line (IBL) in which the three dimensions are combined into one balance sheet and income statement. The purpose of this paper, however, is not to develop the TBL model in general terms but to use it as an evaluation framework and practice guideline for sustainable housing renovation. As argued by Elkington, the original idea of TBL was to encourage businesses to manage the wider economic, environmental and social impacts of their operation. The TBL does not 
cover every aspect of reality but it offers a general perspective on sustainability particularly suitable for analysing the conflicts between the different aspects.

\subsection{Defining Sustainability of Housing Renovation and Sustainable Housing Renovation}

Housing renovation is a crucial field for sustainability. On the one hand, housing in general is quite special as a market commodity. Both in theory and in practice, housing markets differ in many respects from the textbook standard competitive market for homogeneous goods (e.g., [24,25]). Arnott [26] presents a long list of 'peculiarities of housing as a good', with eleven entries: necessity; importance; durability; spatial fixity; indivisibility; complexity and multidimensional heterogeneity; thinness of the market; non-convexities in production; importance of informational asymmetries; importance of transaction costs; and near-absence of relevant insurance and futures markets [26-28]. The importance of the transaction and attachment costs in the housing market comes to a head in renovation processes where long-term ambitions of the estate owner or the municipality regarding a certain estate or housing block are confronted with the needs and preferences of sitting residents.

On the other hand, we may also expect a comparatively long-term perspective in the housing sector, where investments in estates and buildings typically have a life time of 50 years or more. At least to serious professional landlords with a long-term perspective on their management, residents' responses to the renovation of their homes and neighbourhoods should represent an important post in the investment calculus. Thus, an efficient renovation process has to address society's ambition, e.g., to build socially mixed and attractive cities as well as the need for a functioning dialogue between the company and the current and potential residents of the property that is renovated. This would make economic, environmental and social sustainability a more complex issue in housing renovation than in many other fields of industry, but it would also motivate an expectation that matters of sustainability would be easier to integrate in the generally long-term perspective of housing construction and management.

Based on the existing definition of sustainability and the TBL model, we define sustainability of housing renovation as the expectation of improving the outcomes of housing renovation for the present inhabitants without compromising the ability of future generations to meet their needs. Therefore, sustainable housing renovation is defined as housing renovation that simultaneously takes into consideration economic, environmental and social aspect of long-term development.

\section{A System Model of Sustainable Housing Renovation}

In this paper, we consider sustainable housing renovation as a system construct with system characteristics manifested in 1) the triple goals of sustainability; 2) the complicated dynamic process and procedures established to carry out specific activities; 3 ) the wide participation and interaction of diverse actors; and 4) the sophisticated institutional environment where various rules, regulations, and routines apply (see Figure 1).

The goals of sustainable housing renovation are the triple goals of sustainability, namely the economic, environmental and social goals. The economic goals for the firms involved are, for example, efficiency and required yield. For the tenant, it is the importance of economically sustainable rent conditions. Environmental goals are related to energy consumption, water consumption and waste management, but also to materials and transportation of materials used during the renovation. Social goals could be preserving cultural heritage, integration of tenants, safety, health and democracy. Notably, these goals need to be seen from a holistic perspective and from the perspective of the different stakeholders involved. Sometimes, the goals are compatible and sometimes conflicting. The goals can be set before, during and after the renovation process. The goals can also be set either specifically for one building/property or generally for a wider range of buildings, as well as for the area in between the buildings and the cluster of buildings. Such diverse goal-setting is common, not least in public housing companies. 


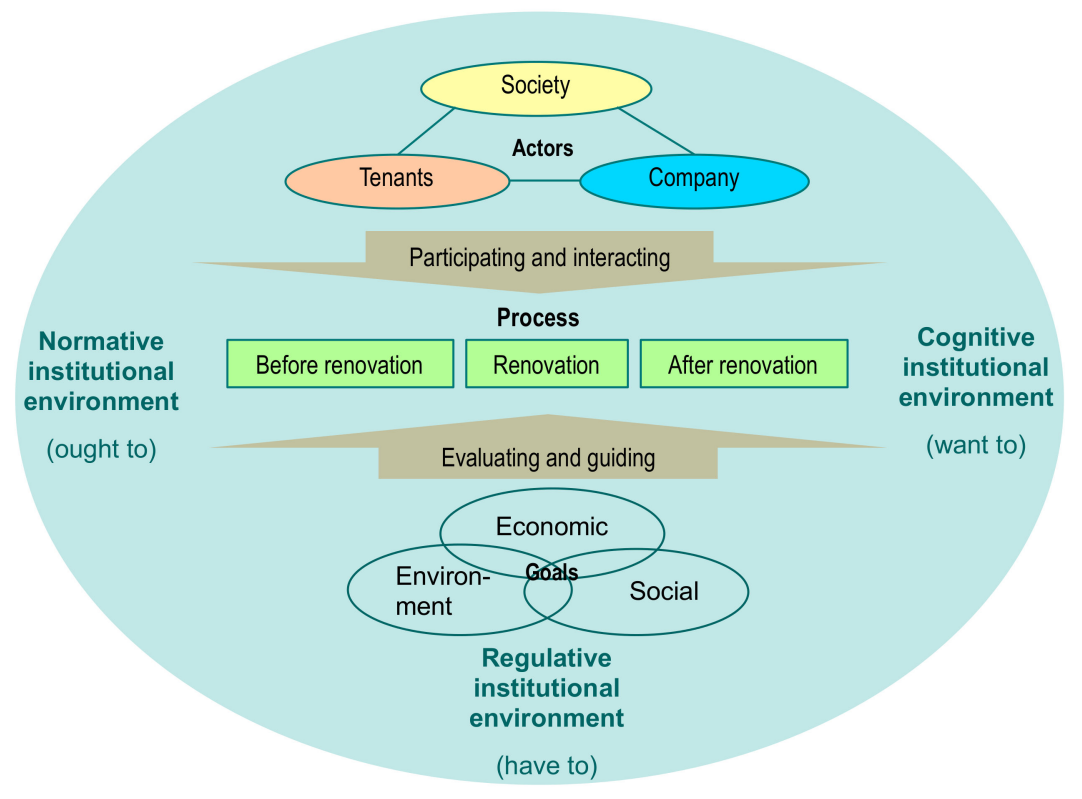

Figure 1. A system model of sustainable housing renovation.

The process of sustainable housing renovation refers to the project process from initiating to closing that is undertaken with long-term economic concerns for the company and environmental and social concerns for the wider society. Typically, the process includes pre-study, design, procurement, construction and closing, but the details can vary from project to project. Even though process is the focus of the framework, it excludes neither the resources used in housing renovation, such as materials, equipment and tools, nor the buildings that are worked on during the renovation process. In practice, the process and the resources are interrelated. The framework also includes the after-renovation stage, which is usually forgotten in research and practice, as part of the processes in question.

The actors of sustainable rental housing renovation include a wide range of stakeholders such as the owner/real estate company, the construction companies, the consultant companies, the sub-contractors, the tenants (and their family and relatives), the neighbourhood residents, the service providers to the buildings, the government regulatory bodies, the city planning authorities, etc. In this paper, for simplicity, we categorised the stakeholders as belonging to one of the three groups. These are the owner/real estate company, the tenants and the wider society (including the community, the NGOs, the local and national authorities, etc.). These actors are directly or indirectly involved in different stages of the renovation processes. They form an actor network where different actors have different strengths and weaknesses, represent different interests, and play different roles. Notably the actor network is a dynamic network during the whole process of housing renovation. The entry and exit of actors may change the dynamics of the network and result in different outcomes in different housing renovation projects.

The institutional environment of sustainable housing renovation refers to the formal rules (constitutions, laws, regulations and standards among others) and informal norms (such as conventions, customs, values and beliefs) that enable and constrain social interaction in the renovation process. This paper perceives institution as rules-of-the-game [29-32]. The institutional theory suggests that institutions, as rules of the game, can be identified as three categories, namely regulative, normative and cognitive [33]. Regulative institutions refer to formal rules, such as laws, regulations, standards and sanctions, contracts and their enforcement through mediation, arbitration or litigation. In most countries, housing is regulated, e.g., through land use policies and construction regulations, as well as more specific rent regulation and tenant protection laws. Normative institutions refer to informal rules, such as work roles, social norms and routines, shared expectations of appropriate behaviour, social exchange processes, etc. For example, in Sweden, it is tradition for the head of the real estate 
company to announce the renovation plan to the tenants and not even his deputy or project manager. Otherwise, it is considered to be improper. Cognitive institutions refer to perceptions of reality, such as shared identities, values, interests, beliefs and assumptions, etc. For example, in Sweden, it is a commonly shared value that the buildings and the people living in the buildings should be respected when renovating. One should not give the tenants too many problems and the original design of the architecture should not be dramatically changed.

Based on the discussion above, the paper forms a system model of sustainable housing renovation, as shown in Figure 1. The core of the model is the renovation process containing the stages of before-renovation, renovation and after-renovation. The actors (firm, tenants and society) interactively participate in the renovation processes at different stages and to differing extents. A sustainable renovation processes is guided and evaluated in terms of the triple goals of sustainability (economic environmental, and social). All these processes are supported or hindered by the institutional environment including regulative, normative and cognitive aspects.

\section{Identifying the Key Challenges of a Sustainable Housing Renovation System}

\subsection{The Challenge of Conflicting Sustainability Goals}

Based on the TBL model, the sustainability of housing renovation can be illustrated as three partially overlapping circles, as shown in Figure 2. The first circle represents the economic goals of sustainability in housing renovation, which is typically related to, for example, the profitability of real estate companies, the economic efficiency of the resource allocation, the growth of the companies and the local economy. The second circle represents the environmental goals of sustainability in housing renovation which usually refers to the performance in terms of energy consumption, water efficiency, waste management, and so forth. The third circle represents the social goals of sustainability in housing renovation which contains broad and sometimes easily overlooked topics, such as cultural heritage protection, community integration, safety, health, democracy and equality in housing, and so forth.

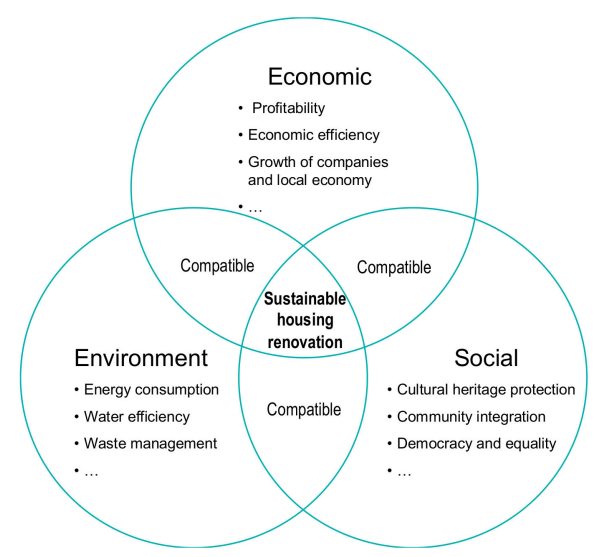

Figure 2. Stylized model of compatible and conflicting goals of sustainable housing renovation.

The economic, environmental and social aspects of sustainability are logically independent but also systematically interconnected by factors at different levels that firms are expected to address at the same time [34]. Sustainable housing renovation is expected to simultaneously target economic, environmental and social goals, as shown in the central compatible part of Figure 2. However, we expect that the ideal situation of simultaneously fulfilling the three goals is typically difficult to reach. It is true that in some cases, a housing renovation solution for reaching one goal may be beneficial also to another goal. For example, recycling building material can save money and benefit the environment at the same time. Such a case lies in the overlapping segment of the economic and environmental circles in Figure 2, where the economic and environment goals are compatible. In other cases, in contrast, a housing renovation solution for reaching one goal may be detrimental to another 
goal. For example, the increasing use of environmentally friendly construction materials may, in some cases, harm the profitability of a real estate company. In this case, there is a conflict between the economic and environmental goals. This creates a dilemma for the company's decision making.

In reality, companies tend to prioritise economic goals over environmental and social goals. The prioritisation of the economic aspect of sustainability clearly implies that economic goals are in conflict with the environmental and social aspects on certain occasions. When there is a conflict, economic goals usually win. The reasons are twofold. First, the profit motive is the main motive, if not the only motive, for the existence of a firm. Mainstream economic and management theory posits that the ultimate goal of an enterprise is to make money. A firm, as an economic agency, is the very organisation that has the legitimacy to maximise profit and pursue what is in their own private interest. As a response, the concept of Corporate social responsibility (CSR) has come on the agenda in later years of industrial history. Companies started to recognise CSR as an important task under external pressure from consumers, NGOs and government agencies. Secondly, the survival and existence of a firm, which is based on its economic profitability, is the precondition of any environmentally friendly and/or socially responsible conduct. A bankrupt firm does not have the capacity nor the opportunity to do anything good to the environment and society. Therefore, economic goals cannot be removed from a serious discussion about sustainability. Thirdly, economic goals are usually actualised in the business sphere, while the actualisation of environmental and social depends on a much broader engagement of stakeholders. The operational difficulty to reach such goals is a commonly observed obstacle in housing renovation.

Therefore, one of the key issues of sustainable housing renovation is to enlarge the compatible parts and reduce the conflicting parts of the triple sustainability goals. In a housing renovation project, the challenge of simultaneously addressing the three aspects of sustainability does not lie in the compatible part of the triple goals, where economic benefit can be combined with environmental and social benefits. Obviously, if a certain practice can simultaneously lead to economic, environmental and social benefit, the company will have the motivation to implement it. Instead, the challenge lies in the field where economic benefit is in conflict with the environmental and/or social concerns.

\subsection{The Challenge of Conflicting Stakeholder Interests}

In our system model of sustainable housing renovation, stakeholders are categorised into three groups, namely the owner/real estate company, the tenants, and the wider society including the community, the NGOs, the local and national authorities, etc. Their interests are illustrated in the three partially overlapped circles shown in Figure 3.

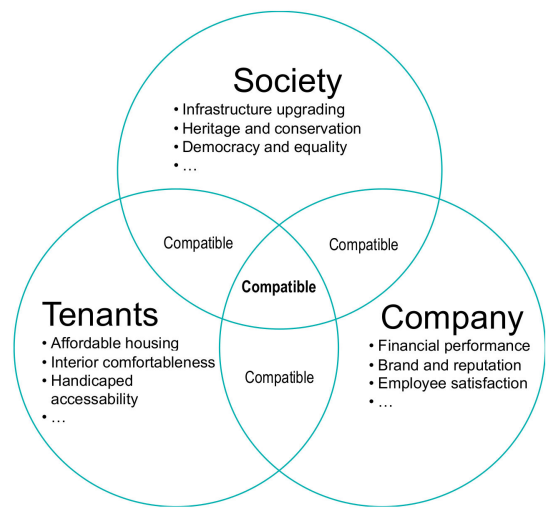

Figure 3. Stylized model of compatible and conflicting interests of stakeholders.

Each of the three different stakeholder groups have their own interests with their own priorities. For instance, the real estate company's interests include financial benefits such as profit, the company's brand and reputation, employees' satisfaction, and so forth. The tenants are interested in affordable 
housing, residential comfort and, to disabled people, the accessibility of the facilities in the building. The wider society has its interests in the housing renovation too. For example, housing renovation can improve the infrastructure and increase the value of the community. It can help the conservation of the cultural heritage, and it can also improve equality and democracy in housing by offering affordable housing to all, including vulnerable social groups.

An ideal situation is when the three different stakeholder groups' interests are compatible, as shown in the centre of the overlapping circles in Figure 3. However, such a situation cannot always be reached. On some occasions, only two stakeholder groups' interests may be compatible. In the worst case, one stakeholder group's interests are totally incompatible with that of the other two groups.

Sustainability in housing renovation, like in many other business processes, needs the simultaneous recognition of the various, often conflicting demands of different stakeholders $[4,35,36]$, many of whom tend to apply different decision logics and preferences than the company managers [37]. The economic, environmental and social interests affected by a housing renovation project are carried out and influenced by a wide range of stakeholders beyond the organisational boundary of the real estate company. Within one of the aspects of sustainability, there may exist conflicts between different stakeholders' interests. For example, the economic benefit of a renovation project can be distributed between the real estate company and the tenants that live in the building. Sometimes this is a zero-sum game, which means a conflict in terms of economic interest between the owner and the users. The environmental impact of the renovation process can harm the inhabitants living close to the building during the renovation but benefit the tenants living in the building after the renovation. In this case, there is a conflict between the environmental interests of the people who live in the building and the people who live in the neighbourhood.

Researchers have argued that firms can benefit economically while they address environmental and/or social challenges [38,39]. The alignment of stakeholder interests is also possible. However, such conflicting goals between different aspects of sustainability and conflicting interests of different stakeholders can typically not be reconciled through traditional business practices [40]. In consequence, addressing the double challenges of conflicting sustainability goals and conflicting stakeholder interests calls for innovation.

\section{Addressing the Key Challenges of Sustainable Housing Renovation by Innovation}

\subsection{An Innovation Approach for Sustainable Housing Renovation}

This paper employs an innovation approach to address the key challenges in the sustainable housing renovation system from a real estate company's perspective (see Figure 4). The sustainable housing renovation system and its key challenges are defined, identified and discussed in previous sections. This section defines and discusses innovation.

In the centre of the framework is the sustainable housing renovation system (see Figure 1 for its components and relations). The sustainability outcomes (economic, environmental and social) are reported and evaluated by means of the TBL model. Here, the TBL model functions as an evaluating structure [12] as well as a practice guideline for sustainability [13]. The conflicting sustainability goals and the conflicting stakeholder interests are the key challenges. The key challenges are identified based on the analysis of the sustainable housing renovation system where diverse stakeholders interact during the renovation process within the constraints of the institutional environment. 


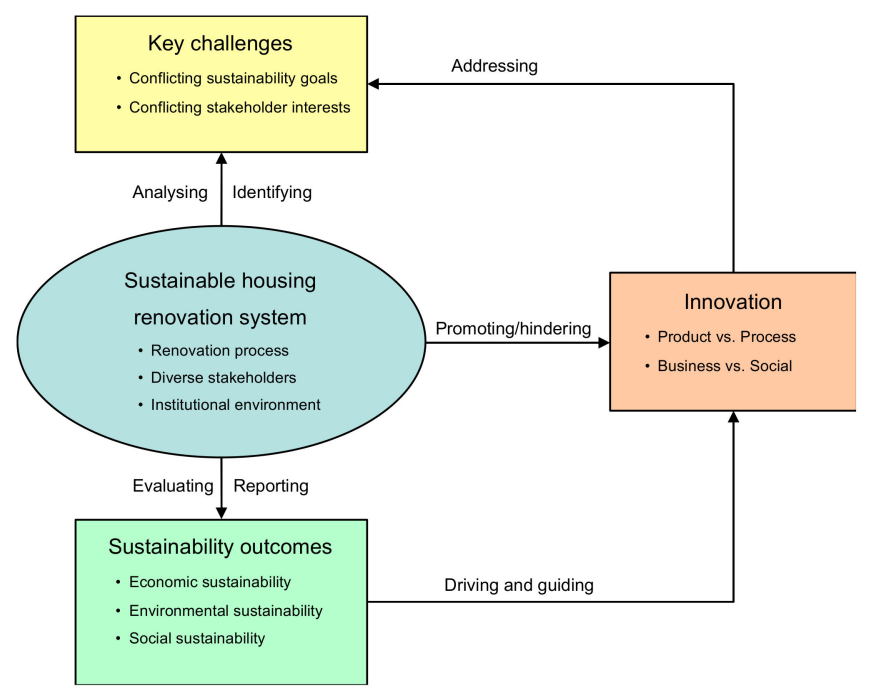

Figure 4. An innovation approach toward sustainable housing renovation.

There are three crucial relations between innovation and the sustainable housing renovation system, the sustainability outcomes and the key challenges of the system. Firstly, innovation is used as a tool to address the key challenges in the system. Secondly, innovation is driven and guided by the triple sustainability goals [41]. Thirdly, innovation is promoted or hindered by the process, actors and institutional environment of the system $[29,31]$.

\subsection{Innovation in Sustainable Housing Renovation}

Innovation is a multi-dimensional concept. There are different typologies of innovation. For addressing the key challenges in sustainable housing renovation, this paper adopts the product-vs.-process innovation and business-vs.-social innovation typology.

\subsubsection{Product Innovation and Process Innovation}

The adoption of the product-versus-process innovation typology in our innovation approach gives room for further identification of different types of innovation which, on the one hand, occur in the production and process of housing renovation, and, on the other hand, are specifically related to technology, organisational structure, organisational methods, business model, and so forth. The product-process innovation typology is better suited to a general model of a housing renovation system than other innovation typologies, such as incremental-versus-radical, disruptive-versus-sustaining, etc.

A product innovation refers to the introduction of a good or service that is new or significantly improved to the market [42]. Product innovation in housing renovation includes significant improvements in technical specifications, components and materials, incorporating software, user-friendliness or other functional characteristics of the buildings. Notably, product innovation can be both the creation of a new product or service and the new use of an existing product or service. Production innovation in housing renovation can be, e.g., the introduction of self-cleaning hydrophilic coating for building exteriors which is able to maintain itself and chemically break down adsorbed dirt in sunlight, or vacuum tube windows which can effectively prevent heat losses.

A process innovation is the implementation of a new or significantly improved production or delivery method which includes significant changes in techniques, equipment and/or software [42]. The process of housing renovation is a combination of facilities, skills and technologies that are used to renovate the buildings and provide services. Process innovation initiatives in housing renovation can result from the introduction of new construction materials, new construction machineries and technologies, new project management software, etc. It can also concern the re-design of the organisation, the introduction 
of new management methods and new ways of delivering a service. Process innovation in housing renovation can be intended to decrease unit costs of production or delivery of renovation projects, to increase quality or to produce or deliver new or significantly improved renovation processes and results. One example is the introduction of social media such as Facebook and Twitter, and in some cases, self-developed apps, to the renovation process as a communication tool between the real estate company and the tenants. Such devices can be used by the project manager to inform about renovation progress, and to receive complaints and suggestions from the tenants. It creates a temporary community where the real estate company and the tenants work together to ensure a smooth renovation process and sometimes, co-create new practices to improve the quality of the renovation project.

\subsubsection{Business Innovation and Social Innovation}

The adoption of the business-versus-social innovation typology in our innovation approach corresponds with the distinctive social dimension of housing as a product embedded in a specific socio-economic context and a product that is closely related to people's daily life, wellbeing and identity. The social dimension of housing provides tenants with motivation and capability to help solving problems in housing renovation.

Business innovation refers to innovation that aims at solving a problem in order to make a profit. It is using business means to make business profit. It is business both in its ends and its means. In contrast, social innovation refers to innovation that is social both in its ends and its means [43]. It means using social forces, such as individuals, NGOs and communities, to solve social problems.

The idea of social innovation has gained increasing attention for its recognised bottom-up approach and notable capacity to address urban problems [44], including those related to such housing renovation that risks creating negative outcomes in terms of sustainability. The pressure of offering affordable and high-quality housing to vulnerable social groups, such as elderly people, unemployed people and newly arrived immigrants, has pushed real estate companies and public authorities to go beyond conventional ways of doing business and looking for innovative options of offering social welfare.

In many countries, such as Sweden, Italy and the Netherlands, public administration has enlarged urban public policies to promote social innovation and the ecological sustainability of buildings [45]. Public and commercial real estate companies are also trying to use social innovation to smooth and improve their rental housing renovation projects. In Helsingborg, Sweden, the municipality's real estate company Helsingborgshem initiated a new housing project aiming at social integration of the old and the young, as well as the local and the foreign population. The city is facing increasing housing shortage and social segregation due to unemployment and immigration. The project of social innovation is named SällBo. It is based on the new housing concept of conviviality and co-living. The previous homes for the elderly have been renovated into a new co-living building. More than half of the apartments are rented out to seniors over 70 years old and the rest to young adults between 18 and 25, including young people who recently received a residence permit in Sweden (the new arrivals). This makes SällBo a unique accommodation, where generations and cultures meet and social life is at the centre. The target groups were invited to workshops and meetings during the pre-study period of the renovation. They discussed, together with the real estate company, how to renovate the old elderly home into a new place where social life was actively facilitated. Moreover, the standard facilities in residential buildings, the renovation added communal kitchens, a library, a fitness room, a yoga room, a film room, a studio with art materials, a gaming room, a hairdresser's room, etc. The local community is organised with both time and space for new meetings, exchange of experiences or just company. Residents are selected by interviews, and they are required to be able to speak Swedish and/or English. They should spend at least two hours a week in collective activities and participate in joint decision-making meetings once a month. The slogan on the project website is "Welcome Home!". This is an example of social innovation in housing renovation that aims to solve social problems for sustainability. 


\subsection{The Linear and the Organic Innovation Process Models in Sustainable Housing Renovation}

The innovation process refers to a set of activities from the generation of new ideas and the transformation of these ideas into innovative products and/or processes. There are two different innovation process models, namely the linear model and the organic model.

The linear model sees the innovation process as a planned and controlled process, for example, the technology push model and the market pull model (see [46] for a review). In these two models, the product or service concept is frozen and criteria are set at the early stage of the process, after which gatekeepers decide on the continuity or exit of the process. The innovation process is tightly controlled and planned by the actors and guided by the desired goals that are set in advance. The linear models are suited to situations where change in the environment is slow and the time for innovation is sufficiently long. We expect that the linear models apply to the incremental innovation with fewer actors involved and clear short-term goals set in a relatively certain environment of a housing renovation project, such as small-scale normal maintenance of a building.

The organic model sees the innovation process as an open, learning based, trial-and-error process, such as the cyclic model [47], the funnel model [48], and the neural network model [49]. In the open and flexible innovation process, no concept is frozen and no design is fixed at an early phase; phases can be repeated and actors can enter and exit at any time. The process is continuously driven by customer needs or needs from other part of the system. Diverse actors are involved. The process is orchestrated by different actors over different stages. Thanks to the ambiguity and uncertainty of the process, the organic model of innovation process cannot be planned but be based on learning. This may lead to unexpected, sometimes chaotic results. Nevertheless, it has been argued that organic models are more open and flexible, with more driving actors involved and thus, are best suited in a complicated, ambiguous and uncertain environment, such as a large-scale housing renovation of properties.

An innovation process in housing renovation, which aims to address the challenges of conflicting sustainability goals and conflicting stakeholder interests, is a complex process involving different actors who hold different goals and bear different interests. Research has shown that innovation comes from the interaction of different actors and the heterogeneity of diverse actors is critical to the generation of innovation [50]. Different from conventional housing renovation, sustainable housing renovation calls for innovation targeting not only economic goals but also social and environmental goals. The triple goals of housing renovation are carried by different actors or stakeholders. Consequently, the generation of innovation in sustainable housing renovation is expected to involve more actors in the innovation process than conventional housing renovation. Thus, the well planned and controlled linear models may not work. Instead, we expect the innovation process in sustainable housing renovation to be more of an organic process than a linear process.

\section{Discussion and Conclusion}

This paper develops a system model for understanding sustainable housing renovation as a system phenomenon which has multiple sustainability goals, a complex dynamic process and procedures established to carry out specific activities, the wide participation and interaction of diverse actors, and a sophisticated institutional environment where various rules, regulations, and routines apply. We identified the key challenges of sustainable housing renovation; as the conflicting sustainability goals and the conflicting stakeholder interests. To address these two key challenges, this paper suggests an innovation approach by which innovation is generated preferably through an open, learning based, trial-and-error innovation process within the system context. To illustrate how innovation can be used as a tool to address the key challenges and achieve sustainable housing renovation, product versus process innovation and business versus social innovation in sustainable housing renovation were presented and discussed. Notably, social innovation with its social purpose and social means that differ from the conventional way of doing business provides an innovative option for achieving sustainability in housing renovation. 
This paper does not take the stance of a single actor, such as the real estate company, the municipal authorities, the general public, or the local tenants. Instead, it takes a general view of the sustainable housing renovation processes, the actors that the processes involve, and the institutional environment in which the processes are embedded. All the different stakeholders of a housing renovation project can find their own positions in the model. The system model can be used by firm managers, city planners, regulators, and also by tenants and citizens to understand the complicated system of sustainable housing renovation and to find innovative solutions to address its key challenges.

This model contributes to the sustainability literature with a focus on the TBL model in several ways. First, the model introduces system perspective into the application of TBL model by taking housing renovation as a system in which different groups of actors are engaged at different levels in different phases of the process and sees the institutional environment as a driving and hindering power of the system. One criticism to the TBL model concerned its lack of systematic thinking [51]. The introduction of system perspective into the application of TBL entails the ability of understand the complicated relations, interactions and situations in housing renovation that can hardly be explained by simple cause-and-effect relations. Second, the model introduces an integration focus into the application of the TBL model. The TBL model pays more attention to the co-existence of the three aspects while somehow ignoring their dynamic interdependence [52]. This may lead to "a tendency to ignore the profound interdependence of these factors, and to see them as likely to be conflicting rather than potentially complementary" [19]. It may also encourage a static perspective which assumes that sustainability is about balancing the three aspects within a given total benefit. The integration of the three aspects of the TBL model has two meanings. On the one hand, to enlarge the compatible parts of the projects and realise the potential of synergy between different goals; on the other hand, to reduce the conflicting parts or to minimise the negative impact of these conflicts. Provided an integration focus, the model can be used as a tool to find agreement on mutual supporting activities in relation to all aspects of sustainability.

This is a theoretical paper, although it has been related throughout to existing empirical research and knowledge about rental housing renovation and sustainability from Sweden and other countries. Our model could be further tested, developed, refined and modified by future empirical research, where the theoretical concepts of the model are translated and operationalised into concrete observable social and physical entities, in a similar way as was attempted in this paper. The model could also be tested in practical applications, e.g., where the actors involved in a certain housing renovation process open up a systematic dialogue with the shared purpose of minimizing the segments of incompatible goals of sustainable housing renovation and incompatible stakeholder interests.

Author Contributions: For research articles with several authors, a short paragraph specifying their individual contributions must be provided. The following statements should be used "conceptualization, J.L.; methodology, J.L.; formal analysis, J.L.; B.B.; H.B. and K.S.P.; investigation, J.L.; H.B. and K.S.P.; writing-original draft preparation, J.L. and B.B.; writing-review and editing, J.L.; B.B.; H.B. and K.S.P.; visualization, J.L.; project administration, H.B.; funding acquisition, J.L.; B.B.; H.B. and K.S.P.". All authors have read and agreed to the published version of the manuscript

Funding: This research was funded by Mistra Urban Future, an international research and knowledge centre for sustainable urban development. The project is entitled Innovation and Sustainability in the Real Estate Industry: Processes of Housing Renovation.

Acknowledgments: We would like to express our gratitude to the two real estate companies, HSB Sundsfastigheter, Malmö, Sweden and Helsingborgshem, Helsingborg, Sweden for their great and generous support to our research in housing renovation, as well as for the fruitful discussion on our system model and innovation approach for sustainable housing renovation.

Conflicts of Interest: The authors declare no conflict of interest. 


\section{References}

1. Meijer, F.; Visscher, H.; Nieboer, N.; Kroese, R. Jobs Creation through Energy Renovation of The Housing Stock. Neujobs. 2012. Available online: http://conference.iza.org/conference_files/neujobs_2014/4 (accessed on 8 December 2019).

2. Farsäter, K.; Strandberg, P.; Wahlström, A. Building Status Obtained before Renovating Multifamily Buildings in Sweden. Journal of Building Engineering 2019, 24, 100723.

3. Elkington, J. Towards the Sustainable Corporation: Win-Win-Win Business Strategies for Sustainable Development. Calif. Manag. Rev. 1994, 36, 90-100. [CrossRef]

4. Ástmarsson, B.; Jensen, P.A.; Maslesa, E. Sustainable Renovation of Residential Buildings and the Landlord/Tenant Dilemma. Energy Policy 2013, 63, 355-362. [CrossRef]

5. Lind, H.; Annadotter, K.; Björk, F.; Högberg, L.; Klintberg, T.A. Sustainable Renovation Strategy in the Swedish Million Homes Programme: A Case Study. Sustainability 2016, 8, 388. [CrossRef]

6. Du Plessis, M. The Role of Knowledge Management in Innovation. J. Knowl. Manag. 2007, 11, $20-29$. [CrossRef]

7. Baregheh, A.; Rowley, J.; Sambrook, S. Towards A Multidisciplinary Definition of Innovation. Manag. Decis. 2009, 47, 1323-1339. [CrossRef]

8. Stirman, S.W.; Kimberly, J.; Cook, A.; Calloway, A.; Castro, F.; Charns, M. The Sustainability of New Programs and Innovations: A Review of the Empirical Literature and Recommendations for Future Research. Implement. Sci. 2012, 7, 17. [CrossRef]

9. Thuvander, L.; Femenías, P.; Mjörnell, K.; Meiling, P. Unveiling the Process of Sustainable Renovation. Sustainability 2012, 4, 1188-1213. [CrossRef]

10. Hart, S.; Milstein, M. Creating Sustainable Value. Acad. Manag. Perspect. 2003, 17, 56-67. [CrossRef]

11. UN (United Nations). Our Common Future: The World Commission on Environment and Development; Oxford University Press: Oxford, UK, 1987.

12. Goel, P. Triple Bottom Line Reporting: An Analytical Approach for Corporate Sustainability. J. Finance Account. Manag. 2010, 1, 1:27-42.

13. Rogers, K.; Hudson, B. The Triple Bottom Line: The Synergies of Transformative Perceptions and Practices of Sustainability. OD Pract. 2011, 4, 3-9.

14. Elkington, J. Enter the Triple Bottom Line. In The Triple Bottom Line: Does It All Add Up; Henriques, A., Ed.; Routledge: London, UK, 2013; pp. 23-38.

15. Elkington, J. Partnerships from Cannibals with Forks: The Triple Bottom Line of 21st,ÄêCentury Business. Environ. Qual. Manag. 1998, 8, 37-51. [CrossRef]

16. Hauge, Å.L.; Thomsen, J.; Lofstrom, E. How to Get Residents/Owners in Housing Cooperatives to Agree on Sustainable Renovation. Energy Eff. 2013, 6, 315-328. [CrossRef]

17. Llera-Sastresa, E.; Scarpellini, S.; Rivera-Torres, P.; Aranda, J.; Zabalza-Bribián, I.; Aranda-Usón, A. Energy Vulnerability Composite Index in Social Housing, from A Household Energy Poverty Perspective. Sustainability 2017, 9, 691. [CrossRef]

18. Robins, F. The Challenge of TBL: A Responsibility to Whom? Bus. Soc. Rev. 2006, 111, 1-14. [CrossRef]

19. Sridhar, K.; Jones, G. The Three Fundamental Criticisms of the Triple Bottom Line Approach: An Empirical Study to Link Sustainability Reports in Companies Based in the Asia-Pacific Region and TBL Shortcomings. Asian J. Bus. Ethics 2013, 2, 91-111. [CrossRef]

20. Gibson, R. Beyond the Pillars: Sustainability Assessment as A Framework for Effective Integration of Social, Economic and Ecological Considerations in Significant Decision-making. Journal of Environment Assessment Policy and Management 2006, 8, 259-280. [CrossRef]

21. Lozano, R. Towards Better Embedding Sustainability into Companies' Systems: An Analysis of Voluntary Corporate Initiatives. J. Clean. Prod. 2012, 25, 14-26. [CrossRef]

22. Bratt, R. The Quadruple Bottom Line and Nonprofit Housing Organizations in The United States. Hous. Stud. 2012, 27, 438-456. [CrossRef]

23. Scrimgeour, F.; Iremonger, C. Maori Sustainable Economic Development in New Zealand: Indigenous Practices for The Quadruple Bottom Line; University of Waikato: Hamilton, New Zealand, 2004.

24. Gibb, K.; O'Sullivan, T. Housing Economics and Public Policy: Essays in Honour of Duncan Maclennan; Blackwell Science: Oxford, UK, 2003. 
25. Fallis, G. Housing Economics; Elsevier: Oxford, UK, 2014.

26. Arnott, R. Economic theory and housing. In Handbook of Regional and Urban Economics; Edwin, S.M., Ed.; Elsevier: Amsterdam, The Netherlands, 1987; Volume 2, pp. 959-988.

27. Stahl, K. Microeconomic analysis of housing markets: towards a conceptual framework. In Microeconomic Models of Housing Markets; Beckmann, M., Krelle, W., Eds.; Springer: Berlin, Germany, 1985; pp. 1-26.

28. Harsman, B.; Quigley, J. Housing Markets and Housing Institutions: An International Comparison; Kluwer Academic Publishers: London, UK, 1991.

29. Lundvall, B.-A. Introduction. In National Systems of Innovation: Towards A Theory of Innovation and Interactive Learning; Lundvall, B.-A., Ed.; Anthem Press: London, UK, 1992.

30. Johnsson, B. Institutional Learning. In National Systems of Innovation: Towards A Theory of Innovation and Interactive Learning; Lundvall, B.-A., Ed.; Anthem Press: London, UK, 1992; pp. 23-44.

31. Edquist, C. Reflections on the Systems of Innovation Approach. Sci. Public Policy 2004, 31, 485-489. [CrossRef]

32. Asheim, B.; Gertler, M. Regional Innovation Systems and the Geographical Foundations of Innovation. In The Oxford Handbook of Innovation; Jan, F., Mowery, D., Nelson, R., Eds.; Oxford University Press: Oxford, UK, 2005; pp. 291-317.

33. Scott, W.R. Institutions and Organizations: Ideas and Interests; Sage: Los Angeles, CA, USA, 2008.

34. Hahn, T.; Preuss, L.; Pinkse, J.; Figge, F. Cognitive Frames in Corporate Sustainability: Managerial Sensemaking With Paradoxical and Business Case Frames. Acad. Manag. Rev. 2014, 39, 463-487. [CrossRef]

35. Clarkson, M. A Stakeholder Framework for Analyzing and Evaluating Corporate Social Performance. Acad. Manag. Rev. 1995, 20, 92-117. [CrossRef]

36. Maon, F.; Lindgreen, A.; Swaen, V. Thinking of the Organization as A System: The Role of Managerial Perceptions in Developing A Corporate Social Responsibility Strategic Agenda. Syst. Res. Behav. Sci. Off. J. Int. Fed. Syst. Res. 2008, 25, 413-426. [CrossRef]

37. Hahn, T. Reciprocal Stakeholder Behavior: A Motive-Based Approach to the Implementation of Normative Stakeholder Demands. Bus. Soc. 2015, 54, 9-51. [CrossRef]

38. Dentchev, N. Corporate Social Performance as A Business Strategy. J. Bus. Eth. 2004, 55, 395-410. [CrossRef]

39. Husted, B.W.; de Jesus Salazar, J. Taking Friedman Seriously: Maximizing Profits and Social Performance. J. Manag. Stud. 2006, 43, 75-91. [CrossRef]

40. Martin, S.; Brannigan, J.; Hall, A. Sustainability, Systems Thinking and Professional Practice. J. Geogr. High. Educ. 2005, 29, 79-89. [CrossRef]

41. Nidumolu, R.; Prahalad, C.K.; Rangaswami, M.R. Why Sustainability Is Now the Key Driver of Innovation. IEEE Eng. Manag. Rev. 2015, 43, 85-91. [CrossRef]

42. OECD. The Measurement of Scientific and Technological Activities: Guidelines for Collecting and Interpreting Innovation Data: Oslo Manual, 3rd ed.; OECD: Paris, France, 2005; p. 163.

43. Murray, R.; Caulier-Grice, J.; Mulgan, G. The Open Book of Social Innovation; National Endowment for Science, Technology and the Art: London, UK, 2010.

44. Hargreaves, T.; Hielscher, S.; Seyfang, G.; Smith, A. Grassroots Innovations in Community Energy: The Role of Intermediaries in Niche Development. Glob. Environ. Change 2013, 23, 868-880. [CrossRef]

45. Galdini, R.; Lucciarini, S. Social Innovation and Environmental Sustainability in Social Housing Policies: Learning from Two Experimental Case Studies in Italy. Differ. Strateg. Hous. Design 2019. [CrossRef]

46. Godin, B. The Linear Model of Innovation: The Historical Construction of An Analytical Framework. Sci. Technol. Hum. 2006, 31, 639-667. [CrossRef]

47. Gomory, R. From the 'Ladder of Science' to the Product Development Cycle, Scout for Technology, Design for Manufacture, Shorten the Time to Market. Harv. Bus. Rev. 1989, 67, 99-105. [PubMed]

48. Wheelwright, S.C.; Clark, K.B. Revolutionizing Product Development: Quantum Leaps in Speed, Efficiency, and Quality; The Free Press: New York, NY, USA, 1992.

49. Zeeman, E.C. Differential Equations for the Heart Beat and Nerve Impulse. In Biological Processes in Living Systems: Towards a Theoretical Biology; Waddington, C.H., Ed.; Edinburgh University Press: Edingburgh, UK, 1972; pp. 8-67.

50. Malerba, F. Sectoral Systems of Innovation: A Framework for Linking Innovation to the Knowledge Base, Structure and Dynamics of Sectors. Econ. Innov. New Technol. 2005, 14, 63-82. [CrossRef] 
51. Doppelt, B. Leading Change Toward Sustainability: A Change-Management Guide for Business, Government and Civil Society; Routledge: London, UK, 2017.

52. Hahn, T.; Preuss, L.; Pinkse, J.; Figge, F. Tensions in Corporate Sustainability: Towards an Integrative Framework. J. Bus. Ethics 2015, 127, 297-316. [CrossRef]

(c)

(C) 2020 by the authors. Licensee MDPI, Basel, Switzerland. This article is an open access article distributed under the terms and conditions of the Creative Commons Attribution (CC BY) license (http://creativecommons.org/licenses/by/4.0/). 